\title{
INTRODUCTION 1940
}

(The following opening word was to have been published in our first issue of the year 1940)

It is under very peculiar circumstances that Synthese enters upon its fifth year. Much has been changed since a few years ago we drew up our comprehensive working-scheme. But the great battle then raging between ideas and expressions of will is raging still, and is perhaps keener, fiercer, more inexorable. From the beginning our workingscheme left room for diverging conceptions and convictions. It wanted to express the consciousness, that it is the very variety of means of expression, especially in the range of will and emotion, which may greatly enrich and widen thought in a certain period. This, however, did not prevent us from opposing a "thinking" which of ten wraps itself in a philosophical or scientific garb, but which on critical consideration may not claim the name of philosophy nor that of technical science.

Gradually in the four years of our existence greater unity had come in our striving after clearness of language and insight in the "meaning" of our own word and the word of others. Unity with regard to the trend to be followed, unity too with regard to the methods to be used. And this growing unity was attended by a growing distrust of the means of expression of which both the philosopher and the specialist make use, the language. It came to be more and more evident to us that certain faults inherent in an ever so cautious use of the language are too of ten overlooked in (technical) scientific and philosophical literature. This literature, not in the last instance the philosophical and psychological branch, has grown accustomed to such a degree to division into trends, points of view and systems, that it looks as if it had pretty much given up the idea of an activity aiming at unity. Dogmas over against doctrine, points of view against knowledge, thought-constructions which bar the way for systematical research, concentration upon things one does not know or does not yet know.

A reaction upon and against this attitude has arisen the last few decades. People begin to see through the dualistic character of the language. The critical thinker who is faced with sharp contrasts of words, asks himself more and more; is this a matter of two kinds of terminology or of two kinds of reality? He penetrates deeper than half a century ago into the difference of the means of expression between "experiencing" and "knowing" even if, perhaps he draws the borderline between the two areas too sharply. The problem of "meaning" has claimed its place in full.

Questions arise which touch the core of the current ethical way of thinking. Apriorism is being undermined. What do we mean, people ask, when we say: man "wills", "ought to", "may" and "must"? Recent trends in ethics are aiming at a description of the complex of phenomena to which these and similar terms refer. To use a term of Brun- 
ner's, there is an urgent need of "Begriffsbereinigung" as a basis of fertile positive study. The same thing applies to the philosophy of religion: "Auf's erste müssen wir der Sprache kundig werden" (Luther) i.e. we must know what we are talking about.

A similar view is found in mathematics. Do the mathematical fundamental concepts lie anchored for ever in the human mind? Or is it, as our compatriot Brouwer thinks: that the basis of the mathematical way of thinking is formed by opinions or assumptions, which intuition makes us look upon as evident, but which cannot he caught once for all under a system of axioms? Having been unsettled already by the intuitionism of Poincare and Couturat, the century-old authority of the mathematical basic concepts, nay even that of the logical principles, has received, as it were the finishing stroke from the neo-intuitionism of Brouwer and Heyting.

But also the old concepts of "time", "space" and "causality" have been robbed of their absolutistic character. How many pseudo-judgments and pseudo-problems have not intruded themselves for centuries into technical science and philosophy, because no distinction was made between psychological and physical concepts and because people omitted to inquire after the "psychical and physical correlative" of words!

Many other questions might be mentioned which have fertilized thought life these latter years and which ought to be investigated further. Such as the question if, between the sciences of matter and the sciences of mind a fundamental difference of method or even a way of "understanding" is tenable or not. And the not less important question, whether the biological phenomena can be expressed as a function of physico-chemical processes exclusively.

It is towards the investigation and clarification of these and similar questions that Synthese wants to co-operate to its best ability. In following this line of conduct it thinks it will be contributing to the keeping up of an old philosophical tradition. If in remote ages philosophy was put on a line with purely theoretical technical research, this indicates that science was then at a stage, at which it saw its chief task in the clarification of its own basic concepts. The emancipation of the technical sciences from their common mother philosophy is the expression of a situation, in which the "meaning" of certain basic concepts had become clear enough to allow of efficient manipulation. That even at the present time ethics and aesthetics and sometimes even psychology pass as sub-divisions of philosophy may, in this trend of thought, be explained in no other way, but that they do not yet dispose of sufficiently clear basic concepts. Rather is their effort as yet chiefly aimed at the "meaning" of their formulations. And lastly: when in a firmly consolidated science the necessity appears of reconsidering the real meaning of its basic concepts and thereby a deeper clarification of the "meaning" is reached, we feel this activity as a philosophical action. Does not the progress of science consist for a large part in a continuous clarification of the meaning of its fundamental statements? 
And does not wisdom aim at making visible the deeper significance of man's belief, expectations and will?

Thus Synthese sees itself faced with a task, which, when it appeared for the first time, it described as clarification of present-day life of thought and emotion. It has been said in jest that philosophy is nothing but "abusing a private terminology invented to that purpose." Nevertheless many great thinkers have known the art of expressing the deepest truths in colloquial words.

In every period words arise, with which it is thought that the great problems of life may be solved as if by magic. What miracles are not expected at the present time of the word: "totality". With the help of this word it is thought that no less than three fundamental problems may be solved: the problem of the relation between the organic and the anorganic (the problem of life), the problem of the relation between the physical and the psychical (the body-soul problem), and the problem of the relation between individuality and collectivity (the communityproblem). In such cases it is thought that the magic glass is in hand which shows clearly the real relations between psychology, biology, physics and sociology. A preference for one thing or the other steals into such terms: for the organic above the anorganic, for the psychical above the physical, for the collectivity above the individual. But science is on the alert; her pass-word: "description, not slogans" is hard to mis* understand in this relation.

It has been remarked earlier: the students of philosophy are often the most obstinate adversaries of the philosophers, the former may be scholars, the latter sages, the former write about philosophy and give battle on the field of dogmas, the latter philosophize. Thus it is that fashionable philosophies often clash with the old tradition of philosophy which aims at clarification of the life-of-thoughi-and-emotion. We have said it already: the latter is the tradition we want to maintain. Hoping to be able to make some contribution to a "new thinking" which will know how to beware of false notions and sham wisdom.

The Editors 